\title{
A formação inicial do professor de química em uma instituição de EPT: experiências nas aulas de cálculo e geometria analítica
}

The initial training of the chemistry teacher at an EPT institution: experiences in calculus classes and analytical geometry

- Denis Ribeiro Carvalho , Naires de Cássia Nunes Morais²

\section{RESUMO}

O presente artigo visa a retratar a experiência vivida na disciplina de Cálculo e Geometria Analítica desenvolvida no Curso de Licenciatura em Química do Instituto Federal Farroupilha - Campus Alegrete. Buscamos revelar a importância de se incentivar propostas metodológicas diferenciadas, principalmente em uma instituição de Educação Profissional e Tecnológica, tendo em vista o elevado grau de complexidade das disciplinas exatas no processo formativo dos alunos de graduação. Ressalta-se que estudar e pensar meios para descomplicar o ensino da disciplina de Cálculo é essencial para obter um aprendizado mútuo significativo entre aluno e professor. Assim, pretendemos envolver o leitor em torno da reflexão sobre as contribuições positivas vivenciadas em uma turma de ensino superior, para que, assim, o leitor reflita e utilize como possível material de apoio durante a realização de seu planejamento semestral ou anual. Para isso, ao longo do trabalho, realizamos uma síntese do contexto em que se insere a formação de professores em Instituições de Educação Profissional e Tecnológica, seu compromisso social, seus avanços e possíveis aprimoramentos.

Palavras-chave: Novas metodologias no ensino. Formação de professores. Interdisciplinaridade.

1 Instituto Federal Farroupilha - Campus Alegrete | denis.carvalho@aluno.iffar.edu.br 2 Instituto Federal Farroupilha - Campus Alegrete | naires.morais@iffarroupilha.edu.br 


\section{A formação inicial do professor de química em uma instituição de EPT: experiências nas aulas de cálculo e geometria analítica \\ The initial training of the chemistry teacher at an EPT institution: experiences in calculus classes and analytical geometry}

\section{ABSTRACT}

The present article aims to portray the experience lived in the discipline of Calculus and Analytical Geometry developed in the Course of Graduation in Chemistry of the Federal Institute Farroupilha - Campus Alegrete. We seek to reveal the importance of encouraging differentiated methodological proposals, especially in an institution of Professional and Technological Education, considering the high degree of complexity of the exact disciplines in the undergraduate training process, it is emphasized that studying and thinking means to solve the teaching of the Calculus discipline is essential to achieve meaningful mutual learning between student and teacher. Thus, we intend to involve the reader in reflecting on the positive reflexes experienced in a higher education group, so that the esteemed reader reflects and uses as possible supporting material during the realization of their semiannual or annual planning. In order to do this, we present a synthesis of the context in which teacher training is integrated in Professional and Technological Education Institutions, their social commitment, their advances and possible improvements.

Keywords: New methodologies in teaching. Teacher training. Interdisciplinarity. 


\section{Introdução}

As propostas pedagógicas dos cursos superiores de licenciatura do Instituto Federal de Educação Ciência e Tecnologia Farroupilha possuem como norte legal os Projetos Políticos Pedagógicos. Estes, por sua vez, são elaborados conforme as orientações legais de criação e normatização destas instituições. Dentre os documentos legais que estabelecem o funcionamento, carga horária, diretrizes curriculares e o caminho formativo dos futuros professores estão a Resolução 1/2002 e 2/2002 do Conselho Nacional de Educação. Além disso, a criação, oferta e manutenção de cursos nos Institutos Federais parte, dentre outros fatores, das necessidades de formação profissional da região na qual estão inseridas as instituições em questão.

Conforme o Projeto Pedagógico do Curso (PPC) Superior de Licenciatura em Química, o objetivo é "ofertar ampla formação teórica e prática para os licenciandos, integrando as dimensões específicas e pedagógicas da atuação docente, voltada para a educação básica e educação profissional e tecnológica" (BRASIL,p.9. 2015). Percebemos o compromisso do curso em proporcionar o vínculo necessário e indispensável entre os conhecimentos teóricos e práticos, contemplando as especificidades da docência, considerando as leis em vigor, o conhecimento específico da área e os saberes pedagógicos da atuação docente, direcionados para o pleno exercício profissional.

A disciplina de Cálculo e Geometria Analítica, componente curricular do Curso de Licenciatura em Química, insere-se como etapa formativa dos acadêmicos. Tal disciplina é caracterizada por sua natureza específica enquanto área de conhecimento, pois articula núcloes conceituais provenientes da Matemática: o Cálculo e a Geometria Analítica. Apesar de apresentarem objetos de estudo distintos, os núcleos do Cálculo e da Geometria Analítica perpassam o estudo de outros domínios conceituais, incluindo alguns componentes de interesse da Química.

Assim, para que esta articulação ganhe corpo e sentido para os acadêmicos, é indispensável que se estabeleça uma relação entre este componente curricular e a área de formação docente, além da relação dos conteúdos com o cotidiano. Para isso, é necessário que o professor tenha um olhar crítico sobre o currículo e sobre a própria postura. Principalemnte, no que tange ao desafio de articular os conhecimentos específicos com outras áreas do conhecimento e com a vida em sociedade.

Durante as atividades desenvolvidas ao longo do semestre na disciplina em questão, podemos perceber as contribuições de uma abordagem comprometida com a formação docente em uma disciplina específica. A partir da experiencia vivida, surge o desejo por desenvolver um estudo bibliográfico na busca por elucidar a importância de novas propostas metodológicas que contribuam para a formação docente, que ultrapasse a ideia de priorizar apenas os métodos avaliativos somatórios tradicionais, mas que estabeleça correlações entre conceitos trabalhados e estimule o raciocínio e a compreensão lógica do mundo e das especificidades da ciência.

Frente a isso, passamos a refletir sobre o compromisso assumido pelos Institutos Federais de Educação no que tange à formação de profissionais competentes, que contribuam para a superação da dualidade histórica da Educação Brasileira e apresentamos, a seguir, os resultados do estudo bibliográfico realizado.

\section{A formação de professores e a superação da dualidade na Educação Brasileira}

A história da educação no Brasil nos mostra uma perspectiva dual que favorece os interesses da classe dominante em detrimento aos da classe trabalhadora, o que reforça e justifica a luta de classes. Percebemos que, durante um longo período a educação ofertada aos jovens das classes menos favorecidas era limitada aos níveis primários, dando conta da formação de mão de obra - 
sem necessidade de qualificação escolar -, enquanto que para os filhos das classes mais abastadas eram ofertadas as escolas das artes, das ciências e do direito (MOURA, 2007). Isto reforça a visão hegemônica da organização social e mantendo o distanciamento das classes menos favorecidas ao desenvolvimento humano, cognitivo e tecnológico.

Superar estes pressupostos é urgente e se faz necessário para a construção de uma sociedade mais justa e igualitária, porém, os desafios são ainda maiores quando se trata do acesso ao conhecimento científico e tecnológico. Mesmo com o avanço da Rede Federal de Educação Profissional e Tecnológica nos últimos anos, o acesso a esse nível de escolarização ainda é deficitário. As dimensões continentais do país, as dificuldades econômicas e a escassez de políticas públicas dificultam a ampliação da oferta destas escolas.

Além dos espaços de acesso à educação, as condições de trabalho, opções metodologias e o comprometimento com o desenvolvimento humano são alguns dos fatores determinantes do perfil de estudante e cidadão que estaremos formando. Assim, promover as mudanças necessárias implica, necessariamente, em transformar as abordagens do conhecimento nos diferentes espaços escolares, ou seja, é preciso que o saber escolar ganhe novos significados e que contribua para melhorar a vida dos educandos. Para superar os paradigmas de uma educação dualista é preciso reconhecer a necessidade de transformação na forma como o conhecimento é apresentado aos jovens na escola, o que impacta diretamente na prática pedagógica dos professores.

Dar novos significados ao trabalho docente passa pela formação inicial. É imprescindível que os futuros professores conheçam novos métodos, novas abordagens teóricas e possibilidades que ampliem os conhecimentos a serem construídos dentro da escola. Hoje não podemos dissociar o cotidiano social, político e cultural do trabalho escolar. Ora, se o objetivo da escola é contribuir para a superação dos desafios da vida coletiva, devemos formar sujeitos críticos e conscientes da cidadania, capazes de intervir no contexto social. Então, a prática escolar deve ser pautada em ações que proporcionem o estudo de situações do dia a dia, investindo na autonomia dos alunos e na resolução de problemas.

0 processo de apreensão e compreensão da realidade inclui concepções teóricas e 0 conjunto de técnicas definidos pelo pesquisador ${ }^{1}$ para alcançar respostas aos objetos de estudo proposto. É a metodologia que explicita as opções teóricas fundamentais, expõe as implicações do caminho escolhido para compreender determinada realidade e o homem em relação com ela (MINAYO, 1999, p.22)

As palavras de Minayo (1999) reforçam a importância das opções metodológicas do pesquisador. Aqui entendemos que o professor também deve assumir a postura de pesquisador frente à prática profissional e, portanto, a metodologia utilizada em sala de aula que explicitará o comprometimento com a formação humana e cidadã, seja na escolarização de nível básico ou na formação de nível superior, incluindo os cursos de licenciatura.

Para que possamos formar professores conscientes da importância dos aspectos metodológicos nas futuras práticas profissionais, é necessário que a formação inicial esteja em sintonia com as exigências da ressignificação curricular e com a formação integral dos estudantes. Tais exigências são ainda mais significativas em instituições que assumem legalmente o compromisso social e político de emancipação do cidadão, como é o caso dos Institutos Federais de Educação, Ciência e Tecnologia (IFs), que dedicam, pelo menos, $20 \%$ de suas vagas a cursos de licenciatura, sobretudo nas áreas de ciências e matemática.

1 Entendemos que o professor também precisa assumir a postura de pesquisador em relação aos conteúdos que ensina e à própria formação. 
Considerando-se a historicidade dos conhecimentos e dos sujeitos da aprendizagem, os IFS propõe a formação de professores capazes de diversificar suas práticas profissionais, fazendo da contextualização, interdisciplinaridade e flexibilização curricular ferramentas favoráveis à compreensão de significados e à interação entre os saberes escolares e as vivências dos educandos (BRASIL, p. 2, 2012).

Frente ao exposto acima, cabe a reflexão em torno dos Cursos de Licenciatura em Química e as experiências vividas pelos acadêmicos em seu trajeto formativo, nos diferentes componentes curriculares do curso.

\section{A experiência da formação inicial em uma Instituição de EPT e as aulas de Cálculo}

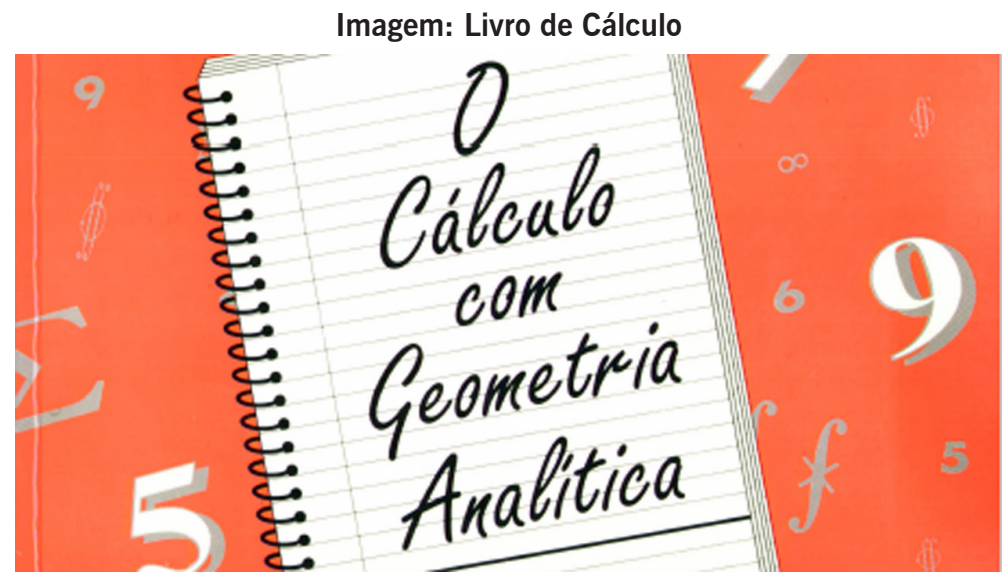

Fonte: Google Imagens

Na disciplina de Cálculo e Geometria Analítica, os alunos têm contato com diversos domínios conceituais específicos da área das ciências exatas, que podem se tornar distantes dos interesses e perderem o significado frente à dificuldade em estabelecer relação entre a docência em Química e os conteúdos da disciplina em questão.

No entanto, cabe ressaltar que o referido curso é ofertado por uma Instituição de Educação Profissional e Tecnológica e, pelo princípio e compromisso ético com a sociedade, qualquer atividade formativa vinculada a esta instituição tem, a priori, o dever de buscar a relação entre os conhecimentos trabalhados em sala de aula e o mundo profissional, além de estabelecer as correlações entre as diferentes áreas do conhecimento e da ciência. Logo, na formação de professores de Química, entende-se que será incessante a busca por relacionar os conteúdos específicos de outras áreas e da própria Química com a docência, traçando uma linha de raciocínio multidisciplinar, uma vez que, no exercício das funções profissionais, o professor em formação precisará lançar mão de conhecimentos de diversas áreas, além dos saberes didático-pedagógicos construídos no decorrer do curso.

Frente a isso, no desenvolvimento da disciplina de Cálculo e Geometria Analítica, podemos destacar as seguintes vivências desenvolvidas:

\subsection{Rodas de conversa}

As rodas de conversa foram realizadas constantemente durante as aulas, com o intuito de adequar o desenvolvimento da disciplina às necessidades e desejos dos alunos. Nestes momentos foram 
decididos como seriam realizadas as atividades em sala e extra classe, quais seriam os instrumentos de avaliação e quais os aspectos quantitativos e qualitativos avaliados.

No que se refere à adequação das atividades extraclasses, considerou-se o fato que muitos acadêmicos são trabalhadores, dispondo de tempo reduzido para o cumprimento das exigências acadêmicas. Assim, acordou-se que o tempo em sala de aula seria otimizado, cumprindo com maior rigor possível os horários e, assim que possível, seriam realizadas aulas extras, o que de fato aconteceu: reunimo-nos em um sábado letivo, realizamos a correção de exercícios, e desenvolvemos um espaço para sanar as dúvidas sobre os conteúdos trabalhados.

Os instrumentos de avaliação foram distribuídos ao longo do semestre, intercalando atividades em grupos, apresentações de trabalho e provas individuais. Buscamos equilibrar os aspectos quantitativos e qualitativos, sempre prezando pela formação de um profissional empático, capaz de refletir a própria prática e colocar-se como sujeito que aprende enquanto ensina.

\subsection{Autoavaliação e avaliações em grupos}

Durante as apresentações dos trabalhos, os acadêmicos puderam autoavaliar-se e avaliar a apresentação dos colegas. Neste processo, foram priorizados os aspectos relacionados ao que consideramos competências essenciais para um professor: domínio do conteúdo, clareza de comunicação, postura respeitosa e dialógica frente aos alunos, valorização dos conhecimentos dos discentes e uso adequado dos recursos disponíveis em sala de aula.

Os aspectos acima citados foram determinados durante as rodas de conversa, a partir da concordância da maioria do grupo.

\subsection{Apresentação do conteúdo}

No decorrer do desenvolvimento da disciplina, os conteúdos formam apresentados de maneira clara e objetiva, podemos perceber a preocupação em manter uma sequencia lógica no desenvolvimento dos conteúdos, sempre buscando a relação do Cálculo e da Geometria Analítica com outras áreas do conhecimento, principalmente a Química.

Em vários momentos, foi possível perceber que a ligação entre os conteúdos da disciplina aqui descrita e os domínios conceituais da Química não era trivial, porém, o domínio do conteúdo por parte da professora, passava aos alunos confiança e credibilidade.

Em todas as ações realizadas, pode-se perceber a importância de o professor criar em sala de aula um ambiente em que os alunos se sintam estimulados a refletir sobre as mais diversas questões do contexto em que vivem, sem deixar de pensar a respeito do papel que exercerão futuramente enquanto profissionais da educação. Independentemente dos conteúdos trabalhados, é preciso que os pressupostos da ciência e da tecnologia sejam vistos como inerentes ao contexto em que os profissionais em formação irão desenvolver as atividades laborais, auxiliando-os na tomada de decisão e na solução de problemáticas do dia a dia.

Para isso, é preciso que os processos de ensinar e aprender estejam calcados em metodologias promotoras da autonomia, da confiança e do diálogo. Para Freire, tanto educador como educando terão que estabelecer um diálogo, a fim de que seja percebida a realidade, ou ainda, que ocorra a percepção do mundo em que se encontram para posterior reflexão, concepção esta que vem ao encontro das necessidades da educação Profissional e Tecnológica.

Neste processo, tanto os acadêmicos quanto o professor colocam-se de forma solidária e colaborativa no processo de construção do conhecimento de seus pares, entendemos que esta postura é fundamental em qualquer nível de ensino, porém ganha ainda mais importância na formação de 
professores, uma vez que trata-se de profissionais que enfrentam no presente ou no futuro desafios semelhantes em suas carreiras e compartilham do compromisso social de formar cidadãos capazes de transformar a realidade.

Seu papel como mediador e questionador em sala de aula é decisivo no processo de ensino-aprendizagem, a relevância da forma como a disciplina de Cálculo e Geometria Analítica foi abordada facilitou e contribuiu para a construção de um aprendizado significativo e da compreensão da sequência lógica existente entre as diferentes áreas do conhecimento articuladas durante o curso em questão. Percebemos, ao longo do percurso, que um dos fatores de maior relevância para alcançar resultados positivos, foi a posição do professor frente à turma, em que ao defrontar-se com a dificuldade dos alunos em relação aos conteúdos, colocou-se como articulador, adequando a metodologia de ensino, de forma que a grande maioria dos discentes sentiu-se seguro e capaz. Assim, entendemos que foi possível construir um aprendizado palpável dentro da realidade do grupo.

É importante salientar a importância e o quão próximos das ciências exatas estão as propostas metodológicas. Enquanto professores, temos que desenvolver um olhar sensivel para perceber as diferenças e as similaridades de nossa sociedade. Uma delas é saber que mesmo os cursos de exatas, possuem uma relação com todas as demais áreas de conhecimento, ou seja, devemos formar professores e desenvolver novas práticas e metodologias que sejam aplicadas em sala de aula.

\section{Considerações Finais}

Ao concluir o processo reflexivo necessário à produção deste artigo, podemos perceber que a forma como a disciplina foi ministrada contribuiu significativamente para a formação individual dos alunos, principalmente nos aspectos relativos à postura mediadora do docente. Ao findar a disciplina de Cálculo e Geometria Analítica, surgiu o desejo de dar continuidade ao processo de reflexão iniciado nas aulas, assim a possibilidade de produzir este relato de experiência nos parece uma grande oportunidade de compartilharmos as nossas vivências.

Pretendemos, contudo, reforçar a importância do papel do professor enquanto apoiador, pois ao nos deslocarmos dos métodos tradicionais comumente adotados na área das ciências exatas, sentimo-nos desafiados e surpresos. Desta forma, diante das dificuldades encontradas em conteúdos que exigem um conhecimento matemático mais específico, tivemos na figura do professor um estimulador na superação dos desafios da formação inicial.

Portanto, foi essencial o auxílio do professor estimulando o potencial de cada um dos alunos, oportunizando momentos de diálogo e construção coletiva. Foi desta maneira que se deu a construção de um conhecimento lógico e objetivo sobre os temas propostos que serão levados ao longo do curso. Além disso, vivenciamos situações de aprendizagem em que encontramos no docente um articulador da formação didática com os conhecimentos das áreas específicas da Matemática e da Química, ou seja, percebemos que é possível articular diferentes domínios conceituais, seja na formação inicial de professores ou em outros níveis formativos.

\section{Referências Bibliográficas}

BRASIL. Ministério da Educação. Contribuições para o processo de construção dos cursos de licenciatura dos Institutos Federais de Educação, Ciência e Tecnologia. Brasília: Setec/MEC. Disponível em: <http://portal.mec.gov.br/dmdocuments/licenciatura_05.pdf> .Acesso em: 12 de jun. de 2018. 
BRASIL. Conselho Nacional de Educação (CNE). Conselho Pleno (CP). Resolução CNE/CP n ${ }^{\circ} 1$, de 18 de fevereiro de 2002. Institui Diretrizes Curriculares Nacionais para a Formação de Professores da Educação Básica, em nível superior, curso de licenciatura, de graduação plena. Diário Oficial da União, Brasília, DF, 9 abr. 2002. Seção 1, p. 31. Disponível em: <http://portal.mec.gov.br/cne/ arquivos/pdf/rcp01_02.pdf>. Acesso em: 8 de jun. de 2018.

BRASIL. Ministério da Educação. Carga horária dos cursos de licenciatura, de graduação plena, de formação de professores da Educação Básica em nível superior. Resolução $n^{0} 2 / 2002$. Diário Oficial da União, Brasília, DF, CNE. Disponível em:<http://portal.mec.gov.br/cne/arquivos/pdf/CP022002. pdf $>$. Acesso em: 8 de jun. de 2018.

BRASIL. Ministério da Educação. Instituto Federal Farroupilha Projeto Político Pedagógico do Curso Superior de Licenciatura em Química. Santa Maria, 2014. Disponível em: <https://www. iffarroupilha.edu.br/projeto-pedag\%c3\%b3gico-de-curso/campus-alegrete>. Acesso em: 1 de junho de 2018.

MINAYO, J.M. Mudar a forma de aprender e ensinar com a internet. In: BRASIL. Salto para o futuro: Tv e informática na educação. Brasília: Ministério da Educação e do Desporto, SEED, 1999. p. 81-90. 